\title{
EMILIO RIBAS
}

\author{
DR. FRANCISCO BORGES VIEIRA \\ Docente-livire de-Higiene da Fac. de Med. da Univ. de S. Paulo e Chefe \\ do Serviço do Inst. de Higiene de S. Paulo.
}

\section{SENHORES ACADEMICOS DO CENTRO OSWALDO CRUZ}

Com o maior prazer e sumamente honrado, acedi ao vosso convite para dissertar sôbre a personalidade de Emilio Ribas e comvosco me congratulo pela vossa iniciativa em procurar exaltar a sua memória, assim como pela efeméride que comemorais, o $270^{\circ}$ aniversário, do Centro Acadêmico Oswaldo Cruz.

E' esta a terceira vez que me cabe a oportunidade de disçorrer sôbre a vida e os feitos de Emilio Ribas e, como das outras, com - mesmo pálido brilho o faço, mas com toda a admiração que em mim desperta a figura de tão notavel quão abnegado brasileiro.

$\mathrm{E}$, por partir a iniciativa de vosso gremio, a memória de Ribas se nos aprésenta de envolta com a desse outro grande patrício, tambem paulista, vosso patrono, Oswaldo Cruz, ao qual igualmente a Pátria tanto deve e que de Ribas foi nã̃o só o amigo, como o irmão de armas, admirando-se mutuamente, estimando-se, ambos tomados pelo mesmo culto acendrado por Hygia e pelo bem da humanidade e nunca rivais a quem interesses subalternos viessem desvirtuar os sentimentos. Efetivamente, a brilhante e prestigiosa associação dos estudantes de medicina da Universidade de S. Paulo, que tem como patrono o fundador da primeira escola de medicina - experimental no Brasil e o saneador da bela Capital Federal, por destinar a noite de hoje ao culto da memória de Emilio Ribas, entrelaça os dois gloriosos nomes, juntos no-los apresenta, e assim recorda o que foram em vida: Ribas, considerando Oswaldo o primus inter pares na Higiene brasileira e mesmo na America do Sul, e Oswaldo, reverenciando em Ribas o experimentado precursor.

Quando, em março de 1903, assumia Oswaldo a direção do serviço federal de Saúde, a convite do grande presidente Rodrigues Alves, e dispunha-se a, de vez, resolver o problema da febre amarela no Rio de Janeiro, dentre os numerosissimos telegramas e cartas de felicitações que recebeu, destacou o de Ribas, então diretor do Serviço

(*) 3. ${ }^{a}$ Conferencia da Serie elaborada pelo Centro" Academico Oswaldo Cruz, para comemorar o $27.0^{\circ}$ añiversário de sua fundação. (24 de Setembro de 1940). 
Sanitário do nosso Estado, como o que mais o comoveu, o que mais gratamente lhe tocou o coração. E para levar a cabo a ingente empreitada, baseou-se Oswaldo Cruz, não sómente nos resultados dos norteamericanos em Cuba, mas tambem nas experiências e observações que Ribas havia executado desde o final do século anterior, em campanha que então já chegava a seu termo, com a extinção em nosso Estado, do flagelo amarílico" que, por longos anos, the tolhera o progresso e lhe roubara para mais de 30.000 vidas.

No Rio de Janeiro, ainda em 1903, grande era a oposição que cncontrava a nova doutrina profilática de transmissão pelo mosquito, dificultando a tarefa a que Oswaldo Cruz deitara ombros. Tal opo= sição só foi dominada, em grande parte, pela apresentação dos resultados obtidos por. Emilio Ribas em S. Paulo. Livre o caminho, pôde Oswaldo dedicar-se ao grandioso prélio, coroado em 1908 com a desaparição do mal que ha 60 anos vinha infelicitando o Rio de Janeiro.

$\mathrm{O}$ arquivo de correspondência da familia Ribas, que me foi dado compulsar, mostra diversos exemplares de cartas de Oswaldo, expondo problemas atinentes ao desenvolvimento da campanha em que se empenhava, sempre em tom de maior amizade e espirito de colaboração.

Bem hajam pois os moços academicos' de S. Paulo, pupilos de Oswaldo Cruz, mas que sabem tambem reverenciar outros grandes nomes de sua terra, entre os quais brilha, em primeira grandeza, o de Ribas, o paulista ilustre que, durante 15 anos, dirigiu, sempre com o maior descortínio e devotamento, o serviço de saúde do Estado de S. Paulo e cuja vida foi totalmente dedicada aos problemas sanitários e sociais que afligiam nossa terra.

Os academicos de medicina de S. Paulo, que desde o início de suas atividades associativas, com inteiro apôio de seus mestres, vêm se destacando na solução de questões médico-sociais, em especial na sífilis, e colaborando intensamente com os poderes públicos em tais atividades, não poderiam deixar de prestar homenagem a Ribas, o esquecido Ribas, o nume tutelar da Higiene paulișta, a quem justiça, muito vagarosamente, vem sendo feita.

Ribas amou os moços, e os moços desta Faculdade eram por êle admirados, pelo muito que se interessavam.e faziam em pról da causa da saúde pública.

Em conferência memoravel que pronunciou no Instituto de Higiene de S: Paulo, em 9 de novembro de 1921, homenageava Ribas não só a Arnaldo Vieira de Carvalho, o saudoso e ilustre fundador desta Faculdade, e ao seu corpo docente, como, em destaque, aos alunos e ex-alunos, aos quais se referia com o maior entusiasmo, deles dizendo: "Esses moços já se distinguem no magistério superior, na direção de laboratórios científicos, na clínica civil e hospitalar, nos nobres mistéres da medicina légal e finalmente na defesa da saúde pública, tendo mesmo fundado, quando nos bancos acadêmi- 
cos, o importantissimo serviço contra as devastações da avaria, problema ëste de grande relevância para a melhoria da nossa raça e que atualmente preocupa a administração de todos os povos civilizados.

"Os diplomados por esta Faculdade, cada um em sua especialidade, honram pois, os seus mestres, e concorrem de um modo evidente para o progresso de São Paulo e do Brasil, levando aos recantos do nossso Estado a magnifica influência social dos generosos sentimentos aninhados nos coraçốes dos moços e cujos efeitos benéficos estão na ràzão direta da cultura científica recebida nesta casa".

Mais adiante

“......... a abnegação desses moços partindo daqui para a cruzada do bem já tinha sido brilhantemente manifestada durante a devastadora gripe pandêmica que assolou por alguns mesés o nosso Estado.

"A lembrança nesta ocasião solene dos dias lutuosos para a nossa terra, é mais uma homenagem que desejo prestar à memória imorredoura do fundador desta Faculdade e aos seus dignos alunos, a alguns dos quais devemos muita gratidão".

$E$ depois de relembrar feitos de abnegação da mocidade de nosso país, continúa:

"Pois bem, meus senhores, Arnaldo'Vieira de Carvalho, superintendente geral dos hospitais ao tempo da devastadora gripe, teve tambem a feliz idéia de apelar para os alunos desta Faculdade, quando o nosso litoral, a nossa bela capital, o interior do Estado e os ser1s longínquos sertões sofriam as dolorosas consequências da destruidora pandemia.

"E o que fizèram os alunos desta Faculdade, sôb a palavra de ordem do seu fundador, na dolorosa emergência, ainda está na memória das pòpulações agradecidas.

"Eles, como os meninos de Floriano, só esperavam a voz de comando do seu diretor e amigo para levarem os socorros necessários aos fócos epidêmicos, mesmo quando localizados nos nossos sertões".

Durante essa quadra triste de gripe, entre os muitos hospitais que se constituiram em S. Paulo, coube a Emilio Ribas dirigir o Hospital do Colégio Diocesano onde vários alunos da Faculdade prestaram serviços excelentes. Honraram a Faculdade, diz Ribas, em oficio dirigido ao Dr. Arnaldo Vieira de Carvalho, por cujo intermédio, agradecia-lhes os valiosos serviços prestados, citando-lhes os nomes. Havia, entretanto, um nome omitido, o de Paulo Bulcão Ribas, seu digno filho, que o destino cruel quiz fosse roubado à virla poucos anos depois de formado. O nome de Paulo 'Bulcão Ribas, que prestou valiosos serviços durante a gripe não só no Hospital Diocesano, como tambem em Santos e em Penápolis, foi todavia, acrescentado, pelo saudoso fundador desta Faculdade, à lista em que a modestia proverbial do pai fizera omitir.

E' portanto justificadissima a homenagem que óra prestais ao grande vulto $e$, além da admiração que todos, principalmente nós 
médicos, tributamos à sua memória, irá tambem um pouco de paga pelo muito que êle vos considerava.

O que êle fêz por S. Paulo e pelo Brasil, proporcionanclo à nossa terra maiores possibilidades de progresso, por meio de sua fecunda e inteligente administração, e, cabe notar," com os parcos recursos da época, foi grandioso e bem merece a gratidão eterna de nosso povo e todas as homenagens dos governantes.

Ainda há cerca de 10 anos, pelo brilhante sanitarista patricio Manuel Ferreira, era ele cognominado - o "Esquecido". Daí para cá a reparação aos seus méritos continúa a deixar larga marğem de débitos, tendo sido ainda poucas as homenagens que se têm prestado à sua lembrança.

O hohmem que, pioneiro na América do Sul, livrou o Estado de S. Paulo das epidemias frequentes e mortíferas de febre amarela e brilhantemente pôde provar de modo, irretorquivel, o acêrto das então novas idéias sôbre a epidemiologia dessa doerç̧a, o homem que debelou surtos epidêmicos graves, que ofereceu resistência eficiènte à peste (que pela primeira vez, batia às nossas portas), que reorganizou em bases seguras o Serviço Sanitário, ainda nem possue, para guarda de seus despojos, o monumento tumular que, autorizado por lei, ha mais de um decênio aguarda execução por parte do Govêrno.

Efetivamente, em 1925, votava o Congresso Estadual um modesto crédito de 50 contos de réis para a ereção de um túmulo a Ribas, como homenagem do govêrno do Estado ao ilustre sanitarista que tanto fizera pela saúde do povo paulista. Mas êsse crédito nunca foi aberto! Em 1936, o então deputado Prof. Maciel de Castro, apresentava um projeto à Assembléia Legislativa, para que, afim de saldar éssa dívida, fizesse o Estado erigir uma herma ao grande paulista nos jardins do Hospital de Isolamento de S. Paulo, de acôrdo com proposta que, quando diretor do Serviço Sanitárìo, tivera eu ocasião de dirigir ao então Secretário da Educação e Saúde Pública. Êsse projeto foi muito discutido, opinando alguns para que fôsșe transformada a homenagem na ereção de um hospital ou outra organização de caráter assistencial-sanitário, não chegando, porém, a proposta, sequer, à segunda discussão.

O seu espirito tutelar é venerado, certamente, pelos nossos sanitaristas e, de acôrdo com as possibilidades, algunas homenagens já têm sido prestadas ao vuilto eminente que ora lembramos, entre elas a medalha de ouro que o Govêrno Paulista the conferiu em rememorando o seu triunfo sôbre a febre amarela e o se dar, em 1932, o seu nome ao Hospital do Isolamento de S. Paulo, teatro de experiências memoráveis aí produzidàs por sua iniciativa, repetindo as realizadas em Havana, e que muito contribuiram para o esclarecimento do problema da transmissão de febre amarela.

Mas, fora disso, e, principalmente, do grande lugar que ocupa no coração dos sanitaristas de S. Paulo, o público em geral ainda o desconhece, ainda é preterido ou ignorado em muitas de suas rea- 
lizações por autoridades pouco informadas, ainda esperam seus restos mortais ás homenagens que lhés são devidas pelos poderes públicos de nossa terra!

Algumas cidades paulistas, nobremente deram seu nome a ruas, mas tal homenagem, por muitas vézes tão barateada, nem chega a merecer destaque. E, em Pindamonhangaba, a herma que lembra sua glorioso figura, deve-se à iniciativa do Exmo: Snr. Embaixador José Carlos de Macedo Soares que, em gesto que muito o enobrece, presenteou-a à cidade natal do benemérito sanitarista.

Tendo o Serviçó Sanitário do Estado de S. Paulo iniciado, em junho de 1936, a publicação periódica dos "Arquivos de Higiene e Saúde Pública", dedicou o primeiro número à sua memória e, nesse sentido, enfeixou-se brilhante contribuição de ilustres contemporâneos seus, como Vital Brasil, Clemente Ferreira, de admiradores como Manoel José Ferreira, além de outros estudos biográficos, reunindo-se, ao mesmo tempo, tôda a documentação histórica sôbre Ribas e a Febre Amarela, existente nos arquivos da repartição que tão sabiamente dirigiu.

$\mathrm{E}$ ainda ha pouco, comemorando Campinas o segundo centenário da sua fundação, o Centro de Cultura Intelèctual daquela cidade, que em uma série de conferências homenageou os grandes vultos que contribuiram para o progresso local, promoveu uma em louvor de Ribas. o saneador da cidade, distinguindo-me com um convite para proferí-la.

Os moços academicos, com esta comemoração, muito se enaltecem, lançando à chama bruxoleante de sua memória, mais um pouco do combustivel para que não se apague. E esteu certo que aos cuidados de tal mocidade, ela se avigorará, iluminando os corações de todos os paulistas, em culto que revelará nada màis do que gratidão e jưstiça.

Emilio Marcondes Ribas nasceu em Pindamonhangaba, neste Estado, aos 11 de abril de 1862. Eram seus pais o Sr. Cândido Marcondes Ribas e D. Andradina Machado Ribas. Em novembro de 1887, após brilhante curso, diplomou-se pela Faculdade de $\mathrm{Me}-$ dicina do Rio de Janeiro, defendendo tese em fevereiro de 1888, sôbre "Morte aparente dos recêm-nascidos".

Após a formatura, passou alguns meses em Pindamonhangaba, para se fixar depois em Tatuí e, posteriormente, em Santa Rita do -Passa Quatro, em ambàs grandemente acatado e estimado.

Ingressou em 11 de setembro de 1895 no Serviço Sanitário do Estado de que então era diretor o Dr. J. J. da Silva Pinto. Como auxiliar do Dr. Diogo de Faria que desde o inicio do Desinfetório Central dirigia esta secção do Serviço Sanitário, serviu não só na Capital, como no interior do Estado, onde tivera ensejo de combater 
várias epidemias, a saber: em Rio Claro, Jaú, Araraquara e Pirassununga, e também na estação de S. Caetano. Do eficiente desempenho que deu a tôdas estas comissões, fala bem alto o oficio de louvor que recebeu do diretor Dr. Silva Pinto, em abril de 1896.

E' enviado em seguida a Campinas, de cuja comissão sanitária logo fôra designado chefe e onde prestou eminentes serviços à causa pública. Em 13 de setembro dêsse mesmo ano de 1896, era nomeado inspetor sanitário efetivo.

$$
* \quad * \quad *
$$

Ainda hoje se rememoram as mortíferas epidemias de febre amarela daquela época, que tanto retardaram o nosso progresso, que tanto nos deprimiam perante o estrangeiro.

A doença, de tal forma se aclimou em nossas plagas que, lá fora, chegaram, injustamente, a dar-lhe a sinonimia de "mal do Brasil". A designação não pegou e nem podia pegar. Não só a doença não era nossa, pois para aqui viera de outras plagas, como, graças a vultós como os de Ribas e Oswaldo Cruz, a situação se modificou por completo, com o triunfo sôbre o então inimigo principal do progresso nacional.

Introduzida a moléstia, provavelmente pela primeira vez no país, em Pernambuco e Baía, em 1686, importada, segundo o médico português Dr. João Ferreira da Rosa que a descreveu, por um navio procedente de S. Tomé, aí não se manteve e, sómente em fins de 1849, primeiro na Baía e depois no Rio de Janeiro e em Santos, fomos realmente invadidos pelo mal, que obteve naturalização no país, sendo expulsa em 1903, do Estado de S. Paulo e em 1908 da Capital Federal. Por muitos anos ainda se manteve em zonas urbanas ou outros núcleos de povoados nas regióes do norte do país, para depois, em modalidade recém-revelada, mas de que já Ribas dera conta, conforme adiante veremos, obstinadamente revelar-se em nossas florestas, rechaçada que foi das cidades, lá procurando ganhar nóvo alento, espreitando ocảsião propicia pára novas invasões urbanas, como possivelmente a que se deu no Rio de Janeiro em 1928, devido ao deplorável abandono das medidas severas contra o mosquito transmissor.

Em fins de 1849, instalaram-se os focos na Baía e no Rio de Janeiro e, ganhando pé nessas cidades e outras da orla maritima, foi iniciando a marcha para o interior.

Também o pôrto de Santos foi invadido logo no inicio. Aí apareceram os primeiros casos naquele mesmo ano de 1849 , iniciando-se um periodo de 54 anos de permanência da doença em território paulista, periodo sómente terminado por efeito dos trabalhos dirigidos por Emilio Ribas, registando-se os últimos casos autóctones, no Estado, em 1903. 
Emilio Ribas calculava em 30.000 o número minima de vitimas em todo o interior paulista, durante êsse periodo, o que, na ocasião, traduziria uma perda de 684:864:000\$000, segundo suas estimativas.

Limitada, no inicio, às cidades da costa, entre elas o Rio de Janeiro e Santos, transpôs a doença, mais tarde, a Serra do Mar, ganhando cidades do interior, tais como Vassouras, Barra Mansa e outras, no Estado do Rio e, em 1888 o interior do Estado de S. Paulo, ocorrendo de início, em Campinas, uma pavorosa epidemia. Durante 10 anos. pagou essa cidade pesado tributo à febre amarela. Assim, após a primeira, em 1888-1889, de grande intensidade, ocor- reram outras nos anos seguintes, ora mais, ora menos violentas até 1897, quando, então, começaram a se fazer sentir os resultados_da campanha sanitária empreendida pelo Dr. Emilio Ribas, diretor da Comissão Sanitária de Campinas desde o ano anterior, saneando-se a cidade, resultados que repercutiram não sómente no tocante à febre amarela, mas também em relação à febre tifoide e outras causas de óbitos. Foi ëste o incentivo que determinou a orientação de Ribas nas campanhas antiamarílicas posteriores.

Aproveitando os caminhos ferroviários, a doença havia se disseminado por várias zonas do Estado, quais fogueiras que, surgiam ora aqui, ora ali, repetindo-se frequentemente, cada verão, nos mesmos lugares.

Tal era o espetáculo que se contemplava quando, em 1898, durante a presidência de Peixoto Gomide, o govêrno de S. Paulo movido, não pelas recomendações políticas, mas pelo brilhante trabalho que vinha desenvolvendo Emilio Ribas, e que se refletia em seus relatórios, veio buscá-lo em Campinas, para exercer o cargo de Diretor Geral do Serviço Sanitário, cargo de que tomou posșe em 2 de maio e que com honra e brilho exerceu durante cêrca de 20 anos, os cinco últimos dos quais e os que se seguiram da data de sua aposentadoria até sua morte, dedicados ao estudo dos problemas da lepra e sua solução em nosso Estado.

Ribas; que tivera anteriormente a direção dos trabalhos para a extinção de uma epidemia de febre amarela em Jaú, estava já desde essa época com suas convicções muito abaladas quanto à aceitação, então geral, da teoria do contágio nessa doença. Embora desde muito já houvesse quem descrêsse do contágio da febre amarela, entre êles o grande Tôrres Homem, era opinião generalizada que a doença se transmitia pelas secreções e pelas roupas contaminadas. Daí as desinfeções rigorosas feitas em tôrno dos casos. Outra corrente, em minoria, batia-se antes para fazer valer a água cómo meio de transmissão, hipótese facilmente afastàdà, pois lugares com água bôa eram tão vitimados pela febre amarela como aqueles em que se podia demonstrar estar a mesma poluida.

Em Jaú, observara Ribas que haviam sido grandemente sacrificados na epidemia os imigrantes recém-chegados da Europa para os trabalhos de lavoura. Impossibilitado de dar alojamento a nume- 
rosos órfãos dêsses imigrantẹs, não teve remédio senão acolhê-los no próprio Hospital de Isolamento, onde facilmente seriam vitimas. da doença, fôsse ela contagiosa." Entretanto, a não ser naqueles que já vinham da cidade com a doença incubada, em que esta, portanto, surgia até cêrca de 5 dias após a chegada ao Hospital, pois a isso costuma ir o período de incubação, os restantes não mais a apreșentavam, apesar de haver muitos amàrelentos no hospital, indicando pois a não contagiosidade da doença.

Por outro lado, Ribas observara a repetição frequente de casos da moléstia, apesar de terem sido os doentes rigorosamente isolados e os domicilios, as roupas e objetos dos mesmos, também, rigorosa- : mente desinfetados.

Ribas, pois, não confiava muito nas medidas anti-contagionistas, então classicamente empregadas no combate às' epidemias amarílicas e representadas principalmente pelo isolamento dos doentes è pelas rigorosas dsinfecções de casas, vestuários, dejeções, etc.; de outro lado, e, ainda mais, pudera observar que a limpeza pública e o asseio dos domicilios, quando bem -praticados, muito influiam sôbre o desénrolar da epidemia, atenuando-a e mesmo dominando-a.

Assim pensando e agindo, saneara Ribas a cidade de Campinas, dando como resultado cessarem suas epidemias em 1898, dois anos untes dos sábios membros da comissão médico-militar norte-americana, Reed, Carrol, Agramonte e Lazear, em èstudos empreendidos em Havana, capital de Cuba, terem confirmado ser a doença veiculada por uma certa espécie de mosquito, (o então chamado stegomyia fasciata, culex fasciatus, culex mosquito', culex toeniatus e outros nomes, e cuja designação própria é Aedes aegypti), como desde muitos anos vinha pregando o médico cubano Carlos Finlay. E' como sabeis, um mosquito doméstico, que põe seus ovos e se cria em cacos de garrafa, em latas velhas e em tôda sorte de receptáculos. comumente encontrados no lixo dos quintais sujos.

Ribas foi, pois, um precursor em Campinas, a tanto o tendo levado sua argúcia e o seu zễlo de observador cuidadoso do desenvolver das epidemias que combatia. Quando teve conhecimento do resultado dos estudos da comissão norte-americana em Cuba, capacitou-se, imediatamente, do acêrto dos novos ensinamentos e a explicação do caso de Campinas the surgiu nítida.

\section{$* * *$}

Vejamos agora a atuação de Emilio Ribas à frente da higiene paulista.

Logo no ano seguinte, em fins de 1899, a cidade de Santos é invadida pela peste, que aí conseguira aportar, trazida provavelmente pelo navio "Rei de Portugal", procedente da cidade do Pôrto, que estava a braços com rude epidemia. Medidas imediatas deviam ser tomadas, com o fim não só de combater a epidemia que se iniciava 
na cidade, como impedir a disseminação, do terrivel morbo, no Estado.

Campos Sales, então presidente da República, ofereceu ao govêrno do Estado auxílio federal, em tão grave emergência; Fernando Prestes delicadamente recusa, em gesto que exprimia a confiança do govêrno do Estado nos técnicos paulistas. Com: o fito de, em situação tão melindrosa para o Estado, colocar o Govêrno à vontade, pede Ribas sua demissão, em janeiro de 1900, negada esta, todavia, pelo presidente Fernando Prestes, que júlgava indispensável os seus serviços, reafirmando a confiança mais absoluta por parte do Govêrno do Estado no seu diretor de saúde pública.

Sem tardança, Ribas estabeleceu serviços de vigilância em Santos e assim pôde surpreender a penetração da doença em seu início e dominá-la, antes que pudesse se disseminar no Estado.

Para lá envia Vital Brasil,' incumbindo-o das primeiras pesquisas; êste, contraindo o mal, foi alvo por parte de Ribas de todo o carinho e atenção, o que mais cimentou a sólida amizade entre os dois ilustres patrícios.

$\mathrm{O}$ sôro antipestoșo que então sómente era fabricado pelo Instituto Pasteur de Paris, e, no Oriente, vinha démonstrando eficiência, inexistia em nossos mercados; os insistentes pedidos do govêrno de S. Paulo ao Instituto Pasteur de Parị não podiam ser atendidos, pois o que se produzzia não chegava para o Oriente. Foi obtida com dificuldade uma partida que, a bordo de un navio francês; aportara a Santos, sôro que serviu para as primeiras aplicações, conforme relata Vital Brasil.

Nessa premência, Ribaśs logo premedita a instalação, entre nós, de um instituto que se incumbisse, imediatamente, da preparação do dito sôro e também da de outros sôros preventivos e curativos. E assim funda o Instituto Butantan, ainda em 1899, a princípio a título precário, organizando-se o mesmó definitivamente em 1901, durante o govêrno de Rodrigues Alves, cabendo a Vital Brasil, desde o início, a sua direção.

Destarte, a chegada da peste a nossas plagas ensejou a criação do nosso grande Instituto Soroterápico, fatò idêntico se operando no Rio de Janeiro, onde, pela mesma causa, se fundou o Instituto de Manguinhos.

A projeção de Ribas nos meios científicos de S. Paulo já era tão grande que, em setembro de 1900 , tencionando a Sociedade de Medicina e Cirurgia fundar uma Escola de Ciências Médicas-Cirúrgicas, foi êle convidado para' ocupar uma de suas cadeiras, a de Anatomia Descritiva.

E' notavel a realização de Emilio Ribas no tocante à campanha contra a febre amarela, que desde dezenas de anos frequentemente causava epidemias em cidades do Estado e, progressivamente alargava seu âmbito de ação; ocasionando enormes prejuizos e perdas de vidas preciosas. 
O próprio Ribas, como inspetor sanitário, já o vimos, tivera ocasião de ser enviado para combatê-la em vários pontos. A despeito do maior esfôrço dispendido, a situação não melhorava. A luta se travava com ardor mas, dada a ignorância sôbre a transmissão, os sucessos que se obtinham aqui ou ali não eram duradouros ou se faziam mercê de empirismo, atacando-se o inimigo por todos os lados.

Eis que, no raiar do século, chega ao seu conhecimento o trabalho memorável que em Cuba, vinha realizando a Comissão Militar Médica Americana, constituida pelos drs. Reed, Carroll, Agramonte e Lazear, com a aquisição de novos e seguros conhecimentos que iriam permitir combate eficiente ao mal. Nessa memoria preliminar, concluiu a dita Comissão: $10^{\circ}$ - que o Bacillus icteroides não era a causa da febre amarela; (Tratava-se de um bacilo já conhecido, o chamado bacilo da cólera dos porcos) ; $2 .^{\circ}$ - que o mosquito servia como hospedeiro intermediário do parasita, confirmando-se assim a alegação anterior de Finlay. A Ribas, já afeito às epidemias do mal amarilico, a noticia trouxe a explicação de vários pontos obscuros que observara, convencendo-o imediatamente, pois de muito antes já suspeitava a verdade; os resultados de Campinas e Santos dissipam em seu espirito pequenas dúvidas remanescentes. Em Campinas, os serviços empreendidos por Emilio Ribas em 1896 e 1898, embora sem visar "diretamente o verdadeiro inimigo, em vista da teoria de então, se tornaram todavia eficazes; por terem concorrido, pelo menos, para sensivel redução dos mosquitos". E de Santos, diz Ribas que, "flagelado ha 52 anos, a febre amarela dęsaparecera também, sôb a forma epidêmica, desde 1901, graças à aplicação empirica da profilaxia havanesa, como atestam vários serviços ali executados e que fatalmente concorreram para grande redução dos agentes transmissores". Vislumbrou logo, que as obras de saneamento realizadas nessas cidades (entupimento de poços, drenagem de águas estagnadas, drenagem do solo, retificação de cursos dágua e, naquele porto, a construção das docas), embora com outros fins, tinham, por contrariarem seus habitos, combatido os mosquitos.

Assim, resolve fazer imediatamente ativa campanha contra o estegomyia, julgando-a a única medida capaz, e em Sorocaba, onde uma grande epidemia se verificara de 25 de dezembro de 1899 a 4 de junho de 1900, fazia executar medidas contra os mosquitos já a partir de janeiro de 1901, decorridos apenas cerca de 3 meses da publicação das conclusões de Havana. E, nota Ribas, foi essa a primeira das grandes epidemias que grassaram no Estado que não se repetiu.

Grandemente combatido, não desanimou. Como'se apontasse causa possivel de erro nas conclusões da Comissão Norte Americana no fáto de ter sido Havana, por muitos anos, foco endêmico de febre amarela, a transmissão podendo-se dar, dizia-se, por outros meios que não o estegomyia, e se quizesse atribuir a melhoria do estado sanitário daquela cidade como também em Santos e Campinas, não ao 
exterminio de mosquitos, mas às desinfecções ou obras de saneamento, procura Ribas convencer os oposicionistas, obtendo do Govêrno autorização para, com A. Lutz, repetir as experiências de Havana na cidade de S. Paulo, desde alguns anos isenta de qualquer epidemia do mal amarílico. Elas tiveram lugar no Hospital de Isolamento, ao qual merecidamente, se deu há poucos anos o seu nome, em fins de 1902 e começo de 1903, revestindo-se tudo do maior rigor científico. Convida uma douta comissão, composta dos Drs. Luiz Pereira Barreto, Antonio Gomes da Silva Rodrigues e Adriano de Barros, para acompanha-las. Teriam por fim "verificar a possibilidade da transmissão de febre amarela pela picada de mosquitos (stegomyia fasciata) infectados por pessôas atingidas dessa moléstia". Foram seguidas de uma segunda série, que verificou a não transmissibilidade por meio de vestuário ou fómites, isto é, objetos contaminados. O primeiro daqueles, nome brilhante na ciềncia paulista, acreditava, conforme conferência sua, produzida na Sociedade de Medicina e Cirurgia de S. Paulo, em sessão de 16 de julho de 1900, antes, portanto de serem apresentadas as conclusóes da Comissão Americana, serem os mosquitos fator importante, como veículo e inoculador do germe de febre amarela, julgando apenas, que se contáminassem por provirem de águas infectadas. Para contornar as objeções às expeciências que iam ser repetidas em S. Paulo, larvas de mosquitos stegomyias fôram colhidas em Itú, onde não existia a doenção e os mosquitos adultos resultantes enviados a S. Simão, onde a 24-XII-1902 fizeram-n'os picar um doente nos primeiros dias, para serem então trazidos a S. Paulo. Ribas, seguido do Dr. A. Lutz e, 16 dias depois, de Oscar Moreira, foram os primeiros a se oferecer à picada inoculadora, seguindo-se três outros voluntários, perfeitamente esclarecidos quanto ao perigo; logo depois, tem início a segunda série de experiências, com outro grupo de dedicados voluntários; para demonstrar e não contagiosidade do excretas. Tornou-se assim perfeitamente confirmada a doutrina havanesa.

Mais tarde, no Rio de Janeiro, uma comissão francesa, composta de Marchoux, Simon e Salimbeni, tinha igualmente oportunidade de confirmar a transmisșão de febre amarela pelo Stegomyia fasciata.

Em 27 de junho de 1903 Emilio Ribas apresenta notável memória no $5 .^{\circ}$ Congresso Brasileiro de Medicina e Cirurgia, reunido no Rio de Janeiro, principalmente sôbre os resultados que, pela execução dos novos métodos, havia obtido no extermínio das epidemias de S. Simão e Ribeirão Preto, em 1902 e 1903 . Em Ribeirão Preto, muito de propósito o confessa, a única medida executada foi o combate aos mosquitos; aí não foram feitas desinfecçôes de casas, roupas ou fómites e os resultados obtidos muito contribuiram para dissipar as dúvidas que ainda perduravam.

Em julho de 1903, Ribas declárava, no 5. ${ }^{\circ}$ Congresso Brasileiro de Medicina e Higiene, que os meios de defesa apregoados pelos contagionistas não tinham valôr algum, e sim as medidas dirigidas contra os mosquitos veiculadores. A doença já estava então praticamente 
banida do Estado, e em 1904, se règistravam, verdadeiramente, os dois últimos casos, cabendọ a S. Paulo a primazia, fora de Cuba, do grande triunfó.

Especialmente convidado, fez tambem uma comunicação em Londres, à Society of Tropical Medicine and Hygiene, em sessão de 19 de fevereiro de 1909, presidida pelo eminente Patrick Manson, onde relatou as suas observações e experiências.

Não se pode dizer, já o frizou Manoel Ferreira, que a doença tenha desaparecido do nosso Estado, mercê do saneamento levado a efeito na cidade do Rio de Janeiro, grande centro endêmico, pelo também glorioso Oswaldo Cruz. O desconhecimento da cronologia dos fátos, poderia realmente fazer acreditar que isso tivesse sucedido, por efeito da teoria dos centros chave, isto é, que o saneamento de grandes centros traria como consequência a extinção da doença em zonas satélites. A esta teoria, ha alguns anos atrás, dava-se a maior importância, chegando mesmo a ter aceitação dogmática. Entretanto, não só se reconheceu a sua falibilidade, como bastaria lembrar que a tarefa saneadora no Estado de S. Paulo se completou em:1903, enquanto que, na Capital Federal, o trabalho foi iniciado posteriormente, ocorrendo os últimos casos da longa série, de quasi 60 anos, em 1908.

Viajando pelo velho mundo, foi Ribas recebido em sociedades científicas, onde expôs suas observações referentes à febre amarela e tambem ao alastrim, tendo recebido honroso convite do govêrno frances; que não poude aceitar, para, com o Dr. Simon, cooperar nos serviços de profilaxia de febre amarela na Martinica.

E interessante recordar que, assumindo aspeto epidemiológico diverso do que antes se afirmava, atacando o homem dentro da mata e não nas cidades, novamente surgiu a febre amarela nos últimos anos, e todos vos lembrais da grande disseminação que, em 1936 e 1937, tomou tal forma em nosso Estado, vinda de Estados vizinhos. Essa modalidade que parecia nova, com a transmissão operada não mais pelo clássico mosquito citadino, o Aedes aegypti, tido como único vetor, mas por outros hematofagos próprios da mata, que veiculariam o virus de animais selvagens a homem, principalmente de macacos infectados, foi revelada pela primeira vez por Soper, em 1932 que a descreveu no formoso vale de Canaan,noEstado do Espirito Santo, cenário do conhecido romance de Graça Aranha. Entretanto em época. em que falar nisso era heresia científica, em uma $2 .^{a}$ conferência dedicada aos estudantes de Medicina de S. Paulo e pronunciada em 1922, Ribas se referia a formas silvestres, "como um protesto aos teóricos que afirmavam ser a febre amarela um mal das cidades", e que tivera ensejo de observar em plena mata virgem, quando da abertura do núcleo colonial "Campos Sales", onde se desenvolveu debaixo de uma intensa forma epidêmica, tendo tambem providenciado para que não fôssé devastado pela terrivel moléstia um aldeiamento de indios mansos no oeste do nosso Estado, imprópriamente chamado sul, no município outrora denớnido S. Sebastião do Tijuco Preto, hoje Pirajú". 
Tal asserção, pouco conhecida, merece ser divulgada para que mais uma vez se avaliem as suas grandes qualidades de observador.

No que toca ao problema da tuberculose, revelou Ribas o maior interesse, tendo como seu grande colāborador a figura reverenciada de' tisiatra e' sanitarista de Clemente 'Ferreirá; além dos saudosos e ilustres Guilherme Alvaro e Vitor Godinho. Do fruto de seus trabalhos, fala alto a idéia realizada do melhor aproveitamento de Campos do Jordão como estação de cura para tuberculose:

Foi-lhe preocupação constante o combate à variola que no Estado, fazia frequentes incursões; para êsse fim, disseminou grandemente o uso da linfa vacinica, incentivando as vacinações e revacinações sistemáticas،

Em 1898, ano em que tomou posse do cargo de diretor do Serviço Sanitário, grassava na Capital forte epidemia de variola, registrandose 345 óbitos, surto que galhardamente venceu.

Teve ocasião de observar as diferenças de ordem clinica muitas vezes apresentadas nos surtos da doença, escrevendo trabalhos a respeito e apresentando-os aos meios científicos.

Tais estudos foram empreendidos durante os surtos que, em 1910, se verificaram em vários pontos do interior do Estado, nas zonas limítrofes com. Minas e Paraná. Identificou a variedade que então se apresentava, de quasi nula mortalidade, ao ammas ou "milk-pox"; que W. E. Korte havia observado no sul da África, sendo que o nome de alastrim, porque era designadá nos sertôes da'Baía tornou-se, por efeito dos trabalhos de Ribas, largamente conhecidos nos meios científicos europeus e americanos. Estuda-lhe a evolução, comparando-a com a da variola clássica, investiga a incidência entre vàcinados e não vacinados, indica a sua importação por sertanejos baianos que aqui vinham como colonos para a lavoura de café. Embora a considere entidade mórbida clinicamente diferente da "variola vera", frisa em apontar que o remédio profilático essencial reside nas vacinações, se bem que a imunidade conferida pela moléstia à vacina e vice-versa parecesse, em algun casos, menos duradoura do que a verificada pela variola.

Sôbre o problema apresentou uma nota preliminar à Sociedaḍe de Medicina e Cirurgia de S. Paulo, em 5 de setembro de 1910, havendo igualmente publicado um trabalho em "Transactions of the Society of Tropical Medicine and Hygiene" em julho de 1911.

$\mathrm{O}$ assunto forneceu margem a amplas discussões, desenvolvidas então em S. Paulo,n o Rio de Janeiro, na Sociedade de Medicina Tropical de Londres e na SociedadedePatologia Exótica de Paris. Polêmicas se travaram tambem pela imprensa leiga, rememorando-se as conceituosas contestações com que Rubião Meira, em uma série de três artigos publicados no "Jornal do Camércio" em 1912, pugnava pelo unicismo, ao passo que o ilustre sabio patricio Luiz Pereira Barreto, em artigo para "O Estado de S. Paulo", via no alastrim uma entidade clinica diversa da variola. Existem até hoje dualistas, mas 
os unicistas, que são a grande parte dos tropicalistas, não deixam de reconhecer uma variedade benigna de variola, muitas vezes em países onde se encontram numerosas pessôas vacinadas, forma aberrante, modificada, e que tende a permanecer fixa em suas passagens.

Algumas vezes se tem verificado coexistirem os dois tipos em epidemias distintas, nas mesmas regiões, sendo as vacinações, para ambas, a arma essencial de combate.

Encarou Ribas o saneamento de Ribeirão Preto e Santos também no tocante à malaria. Átuou com energia na questão da febre tifoide, endemica na Capital, levando a efeito a melhoria das instalações sanitárias domiciliares. Convencido Ribas que, um dos principais alimentadores do estado endêmico de febre tifoide entre nós era a mosca, não só para aí orientou a atuação ao Serviço Sanitário, no afã de melhorar a instalação dos esgotos domiciliares, como muito se interessou para que o problema do lixo da Capital, de alçada municipal, tivesse, pela incineração, destruição conveniente. Foi em consequência desta atuação que a Prefeitura construiu na então Av. Municipal, hoje Dr. Arnaldo, um forno de cremação, que dá consumo a parte do lixo da Capital, não tendo infelizmente o plano o seguimento ideado. E o coeficiente de mortalidade que fôra de 96 por $100.000 \mathrm{em} 1897$, baixou a 11 em 1908 e a 19 em 1912, passando daí em diante a se elevar, mercê de outras causas, como a deficiência de policiamento por falta de pessoal, (de que energicamente se queixou Emilio Ribas ao Governó), o rápido crescimento da Capital sem que os melhoramentos necessários pudessem acompanha-lo e as consequentes e repetidas explosões de transmissão hidrica, situação que só viria a resolver-se pela introdução do tratamento da água pelo clóro, em 1926, ao tempo da administração Paula Souza.

Suas vistas se dirigiram para todos os grandes problemas que se apresentavam à sua frente, tanto os de ordem apidemiológica, como os mais estritamente médico-sociais, cabendo a Ribas a formação do primeiro arcabouço moderno da nossa administração sanitária. Muitas das atuais secções do Departamento de Saúde datam de sua administração.

Organizou eficientemente o policiamento sanitário da Capital e atirou-se à reforma dos prédios insalubres, medida de grande valôr no que toca aos problemas de febre tifoide, tuberculose e de peste. Ao fáto de nossas principais cidades se assentarem sôbre um verdadeiro lençol de cimento, decorrentes das medidas de impermeabilização no solo, medida posta em prática a partir da administração de Ribas, se atribue, em parte, a facilidade com que nelas se limitam os surtos dessa
molestia, que de vez em quando, ameaça explodir.

$\mathrm{Na}$ sua administração foi criada, em substituição ao cargo de consultor técnico, a Secção de Engenharia Sanitária, sob cujos pareceres e diretrizes se vem, desde essa época, delineando a melhoria sanitáría de nossas condições de moradia e outras de suạ alçada. 
Em 1905, resolvido o problema da febre amarela no Estado, voltava mais especialmente suas vistas para as questões de administração referentes à proteção social e inaugura a Secção de Proteção à Primeira Infâcia que, já desde 1901, era objeto de ensaios.

Viajando pelos Estados Unidos e Europa, entre 1908 e 1909, visitou organizações sanitárias, ao mesmo tempo que, nas sociedades sábias, elevava o nome do Brasil.

Em 1911 organizou a Divisão de Higiene Escolar. Cabe-lhe tar bém a fundação do serviço de Profilaxia e Tratamento do Tracomâ. Datam, anida, do período de sua administração, a construção do novo prédio do Instituto Butantan e a do magnifico Hospital de. Isolamento de Santos.

Em de agosto de 1913, deixava a direção do Serviço Sanitário, por ter sido comissionado para ácompanhar os estudos clinicos e métodos terapeuticos modernos empregados no tratamento da lepra, bem como o funcionamento de leprosários modelos, no país e no estrangeiro.

Foi grande o seu devotamento à causa da profilaxia dêste terrivel morbo. Neśse sentido, escreveu várias publicações e fortemente combateu o isolamento em ilhas, devndo-se-lhe, de muito, o êxito da criação do Leprosário de Santo Angelo, sempre se batendo pelo isolamento em melhores condições de conforto, de forma a atrair o leproso. No $1 .^{\circ}$ Congresso Médico Paulista e no $1 .^{\circ}$ Congresso Sul Americano de Dermatologia e Sifiligrafia tomou parte ativa no preconicio de suas idéias sôbre a lepra.

$$
\text { * * * }
$$

Modéstia e inteireza de caráter eram de seu feitio. Homem de bem em toda a linha, dizia que desejava sair da direção do Serviço Sanitário com a mesma hombridade com que aí ingressara e, nesse sentido, ou para deixar ao govêrno inteira liberdade de ação, várias foram as vêzes em que solicitara demissão do cargo.

Sabido é que, havendo se pensado em promover um premio de duzentos contos de réis a ele destinado, pelo muito que fizera em be-nefício da Patria, recusou terminantemente que tal idéia fosse levada a cabo.

Dedicava todas as horas do dia ao bem da saúde pública, realizando verdadeiro tempo integral. Por ocasião de sua aposentadoria, recebeu como paga de toda sua dedicação e de todos os beneficio incalculaveis que prestou ao Estado, nada mais do que uma simples carta protocolar em que se lhe agradecia os bons serviços.

Nos últimos anos de sua vida, apesar de aposentado, merecendo o justo repouso, continuou sempre a pugnar pela saúde pública, devotando-se inteiramente à causa dos hansenianos.

Faleceu em S. Paulo, a 19 de dezembro de 1925, contando 63 anos de idade, tendo devotado toda a sua vida ao bem público; a lem- 
brança de seus feitos e o culto de'sua memória serão sempre reverenciados pelos'sanitaristas desta terra e por todos aqueles que pugnam pela causa de unła pátria sadia e forte.

E vós, meus caros amigos e colegás estudantes de medicina de S. Paulo, estou certo, sereis os obreiros da apoteose de Ribas, que tarda. Em logar de destaque de vossa séde social deveis colocar a fotografia de Ribas, que hoje, com expressiva dedicatoria, vos oferece a 7 Exma. Viuva. O retrato de Ribas vos lembrará, e às gerações academicas que vierem passando, a vida de un médico toda dedicada ao bem público e servirá de estímulo e de exemplo. Oxalá, movido pela vossa voz e pelo vosso entusiasmo moço, despertem-se as consciencias, tanto dos homens de govêrno como dos governados,' e seja feita a Ribas cmpleta justiça, não só nos corações dos brasileiros, como em realizações materiais que lembrem aos vindouros aquele que foi
um grande médico e sanitarista,
um grande benemérito, um grande patriota.

\section{CASA DE SAUDE D. PEDRO II CIRURGIA - MATERNIDADE - ORTOPEDIA}

Aberta a todos os medicos

Rua Figueira, 8- Tel. 3-3141 (Parque D. Pedro II)

SÃO PAULO

HIPERTENÇÃO ARTERIAL - MIOCARDITES - ARTERIOESCLEROSE

C ARDIOS C LER OL.

TONICO CARDIACO ATOXICO

A base de Viscum album - Cactus grandiflora - Cratoegus - Kola - Scila Rodanato de Potassa

Amostras e literaturas a disposição dos srs. Medicos

INSTITUTO CHIMORGAN

CAIXA, 4500

SÃO PAULO 